\title{
The Effect of the Bioactive Glass and the Er:YAG Laser on the Remineralization of the Affected Dentin: A Comparative In Vitro Study
}

\author{
Mohammad Javad Moghaddas ${ }^{1 \#}$, Horieh Moosavi ${ }^{1 \#}$, Sara Yaghoubirad ${ }^{2 *}$, Nasim Chiniforush ${ }^{3^{*}}$ \\ ${ }^{1}$ Dental Material Research Center, School of Dentistry, Mashhad University of Medical Sciences, Mashhad, Iran \\ ${ }^{2}$ Department of Restorative Dentistry, School of density, Mazandaran University of Medical Sciences, Sari, Iran \\ ${ }^{3}$ Laser Research Center of Dentistry, Dentistry Research Institute, Tehran University of Medical Sciences, Tehran, Iran \\ * These authors contributed equally to the work.
}

\author{
*Correspondence to \\ Sara Yaghoubirad DDS, MSc, \\ Department of Restorative \\ Dentistry, School of dentistry, \\ Mazandaran University of Medical \\ Sciences, Sari, Iran \\ Tel: +989112146469, Email: \\ yaghoubirs951@mums.ac.ir \\ Nasim Chiniforush, DDS, PhD; \\ Assistant Professor, Laser Research \\ Center of Dentistry (LRCD), \\ Dentistry Research Institute, Tehran \\ University of Medical Sciences, \\ Tehran, Iran. Tel: +98-2183384000 \\ Fax: +98-2188994824; E-mail: \\ n-chiniforush@farabi.tums.ac.ir
}

Published online March 15, 2020

\begin{abstract}
Introduction: The purpose of this study was to compare the effect of the bioactive glass, the glass ionomer, and the Erbium YAG laser as liners on the remineralization of the affected dentin. Methods: The present study was conducted on 64 healthy extracted human molars divided into 4 groups, 1 control group and 3 experimental groups. After artificially inducing dentinal caries lesions, each of the experimental groups was applied to the cavity floor and then restored with a composite. The samples were stored after thermocycling in an incubator for two months. Finally, the hardness of the cavity floor was measured at 3 depths of 20,50 and $100 \mu \mathrm{m}$ by the Vickers microhardness tester. The dentin conditions underneath the liners were also evaluated with FESEM. Statistical analysis was performed by two-way ANOVA and the post-hoc Games-Howell test $(P<0.05)$.

Results: Among the groups, the lowest microhardness value was in the control group $(P<0.05)$ except at a depth of $100 \mu \mathrm{m}$; therefore, there was no significant difference between the control group and the bioactive glass $(P>0.05)$. The laser group had the highest microhardness value, which was significantly different from the control group $(P<0.05)$. There was a significant difference between the laser and bioactive glass $(P<0.05)$, except at a depth of $20 \mu \mathrm{m}$. The laser and glass ionomer had only a significant difference at a depth of $100 \mu \mathrm{m}(P<0.05)$. The microhardness value induced by glass ionomer was higher than bioactive glass, which in no depth was significant $(P>0.05)$. Partial dentinal tubule occlusion was observed with FESEM in each of the experimental groups as compared to the control group.

Conclusion: The microhardness values were higher in all groups than in the control group. The laser might be more successful in remineralization than the other ones.

Keywords: Bioactive glass, Glass ionomer, Laser, Remineralization
\end{abstract}

\section{Introduction}

Tooth decay is the oldest and most common oral disease in human history. ${ }^{1}$ Dental caries is a dynamic condition in which demineralization and remineralization occur periodically in the tooth structure. Demineralization predominates pathologically. ${ }^{2}$ Dental caries treatment with minimal invasion is important in today's perspective. According to the new rules for cavity preparation, minimum invasions are required to remove only bacterial infection and the structures that have irreversible decay. ${ }^{3}$ Modern treatment of dental decay prescribes the removal of only infected external dentin, while internal dentin, which can be remineralized, remains. ${ }^{4}$

The affected dentin preservation has led to the development of new systems of removing tooth decay for preserving healthy tissue and applying remineralizing agents. ${ }^{5}$

One of these materials is glass ionomers which are the gold standard for releasing fluoride and controlling secondary caries. $^{6}$ They cause remineralization of the surrounding dental tissue and prevent bacterial microleakage through adhesion.?

Another substance used to treat dental caries is the bioactive glass. The initial indication of applying these materials is bone remodeling, ${ }^{8}$ but they are also considered as mineralizing agents in dentistry. In an in vitro study by Vollenweider et al, bioactive glasses were reported to stimulate the mineralization of dentin disks. Therefore, they are a tool for dentin remineralization. ${ }^{9}$

One of the newest techniques studied in recent years to prevent dental caries is laser radiation. ${ }^{10}$ One of the most abundant wavelengths of absorbance that change the

Please cite this article as follows: Moghaddas MJ, Moosavi H, Yaghoubirad S, Chiniforush N. The effect of the bioactive glass and the Er:YAG laser on the remineralization of the affected dentin: a comparative in-vitro study. J Lasers Med Sci. 2020;11(2):160-166. doi:10.34172/ jlms.2020.27. 
structure and composition of the dental tissue by heating is erbium wavelengths. ${ }^{11}$ One of the most important types is the Er: YAG laser (erbium-doped: Yttrium-aluminumgarnet) that can remove the hard tissue of the teeth due to its high absorbance in water and hydroxyapatite. ${ }^{12}$ In a study by Moosavi et al that examined the structural and morphological changes of dentin after irradiation with the Erbium YAG laser, it was found that cavity preparation by the laser increased mechanical properties and chemical compositions and improved tooth decay resistance. ${ }^{13}$

No study has been made so far to compare the effects of bioactive glasses, glass ionomers, and lasers in order to determine which of these are more successful in the remineralization of dentin; therefore, the purpose of this study was their comparison.

The null hypothesis in this study is that there are no differences among the bioactive glass, the glass ionomer, and the laser in dentin remineralization.

\section{Materials and Methods}

The present in vitro study was conducted on 64 healthy extracted human maxillary and mandibular molars. The teeth were extracted for medical reasons with informed consent and approved by a local ethics committee (IR. mums.sd.REC.1394.319). The teeth were cleaned from any residual tissue with pumice and water and then stored in $0.1 \%$ thymol solution at $4^{\circ} \mathrm{C}$. The materials used in this test are shown in Table 1.

\section{Preparation of Samples}

Preparation of class I cavities in approximately the same size (a depth of $4.5 \mathrm{~mm}$ and mesiodistal and buccolingual width of $3 \times 3 \mathrm{~mm}$ ) with high-speed dental diamond bur \# 57 (Tizkavan, Iran) with air-water coolant was done. This study was performed at a distance of about 1 millimeter from the pulp. At the time of teeth preparation, those with pulp exposure occurring in this depth were excluded from this study.

After preparation, the samples were immersed in a demineralizing solution for 30 minutes. This solution was made in the Department of Dental Material of Mashhad University of Medical Sciences using $\mathrm{NaH}_{2} \mathrm{PO}_{4}(2.2 \mathrm{~mm})$, $\mathrm{CaCl}_{2}(2.2 \mathrm{~mm})$, and acetic acid $(2.2 \mathrm{~mm})$, with $\mathrm{pH}=$ 4.8. It should be noted that before the test started, the microhardness of some samples was checked to ensure a sufficient amount of demineralization. Meanwhile, to make sure the demineralized solution only penetrates into the cavity, the remaining parts of the teeth were sealed with adhesive wax (Azarteb, Iran). After artificially inducing dentinal caries lesions, the resulting cavity was wider $(4 \times 4 \mathrm{~mm})$ in depth of $4 \mathrm{~mm}$ to provide clinical conditions for the removal of dental caries that should be more conservative in deep areas. After this stage, the teeth were divided randomly into 4 groups of 16 .

In group I, the cavity was prepared with one-step selfetch adhesive of G-Premio Bond (GC, Japan) according to the manufacturer's instructions and restored with incremental layering of a $2 \mathrm{~mm}$ Clearfil APX composite (Kuraray, Japan) using a halogen light-curing unit (Gnatus, Brazil) with a power of $600 \mathrm{mw} / \mathrm{cm}^{2}$ for 40 seconds.

In group II, the bioactive glass 45S5 (Nikceram, Iran) was applied to the surface of the specimens. The bioactive glass powder was mixed with $0.1 \mathrm{~mL}$ of phosphoric acid $50 \%$ on a glass slab for 1 minute to create a creamy consistency and to be used as a liner. This acidic gel (0.5 $\mathrm{mm}$ thickness) was applied to the surface of the specimens with a microbrush and then restored with bonding and a composite.

In group III, after the cavity was prepared, the depth of the cavity was covered with a Fuji II LC glass ionomer (GC, Japan) (0.5 mm thickness) according to the manufacturer's instructions, and then the restoration was similar to group I.

In group IV, after the preparation of the samples, the Erbium YAG laser (Pluser, Doctor Smile, Italy) was used with a power of $0.5 \mathrm{~W}$ and a frequency of $10 \mathrm{~Hz}$ with water-cooling, and then the teeth were restored by a composite as described earlier.

After the preparation and restoration of all specimens, the teeth were subjected to 10000 thermal cycles between $5^{\circ} \mathrm{C}$ and $55^{\circ} \mathrm{C}$ in the thermal cycler (Nemov, Iran) to simulate intraoral conditions so that the teeth were thermocycled in the water bath at $5^{\circ} \mathrm{C}$ for 30 seconds and for 10 seconds outside the water bath, and then at $55^{\circ} \mathrm{C}$ for 30 seconds and 10 seconds outside the water bath.

Afterwards, they were stored in artificial saliva containing calcium, phosphate, sodium chloride and

Table 1. Materials Used in Research

\begin{tabular}{|c|c|}
\hline Materials & Manufacturers \\
\hline Clearfil APX Composite & \multirow{3}{*}{ Kuraray, Japan } \\
\hline Matrix: Bisphenol A diglycidylmethacrylate, Triethyleneglycoldimethacrylate & \\
\hline Filler: Silanated barium glass, silanated silica, silanated colloidal silica & \\
\hline $\begin{array}{l}\text { G-Premio Bonding, 10-MDP, phosphoric acid ester monomer, dimethacrylate, 4-Met, MEPS, acetone, silicon } \\
\text { dioxide, initiators }\end{array}$ & GC, Japan \\
\hline bioactive glass & \multirow{2}{*}{ Nikceram, Iran } \\
\hline $24.5 \% \mathrm{Na}_{2} \mathrm{O}, 45 \% \mathrm{SiO}_{2^{\prime}} 6 \% \mathrm{P}_{2} \mathrm{O}_{5^{\prime}} 24.5 \% \mathrm{CaO}$ & \\
\hline $\begin{array}{l}\text { Fuji II LC glass ionomer, Powder: alumino-silicate glass, Liquid: polyacrylic acid, 2-hydroxyethyl methacrylate, } \\
\text { HEMA, proprietary ingredient, trimethyl-hexamethylene dicarbamate, triethylene glycol dimethacrylate }\end{array}$ & GC, Japan \\
\hline
\end{tabular}


acetic acid with $\mathrm{pH}=5.8$ that was made in the Department of Dental Material of Mashhad University of Medical Sciences. Then they were placed in an incubator (ThelCo, USA) at $37^{\circ} \mathrm{C}$ for 2 months. After the storage period, the teeth were cut in the middle mesiodistally using a fully automatic cutting machine (Nemov, Iran) (3 degrees of freedom and a diamond disk with $112 \mathrm{~mm}$ in diameter and $0.3 \mathrm{~mm}$ in thickness at $2000 \mathrm{rpm}$ ) with cool water flow. In all cases, the cut was performed in such a way that the major part of the lesion was in one piece and another part was excluded. Also, the samples with a depth of less than $1 \mathrm{~mm}$ from the pulp were excluded from the study and other samples were replaced.

In the next step, the buccal or lingual surface of the teeth was mounted in a self-hardening acrylic resin (ParsDandan, Iran) and the cut surface was further prepared for microhardness testing. The surface was completely polished with 800 and 1200 grit silicon carbide sandpaper (AsiaSayesh, Iran).

After the completion of the sample preparation, the microhardness measurements were performed by the Vickers microhardness tester (MH3 model, Koopa Pazhoohesh, Iran) at the distances of 20,50 and $100 \mu \mathrm{m}$ from the cavity floor restored (in the middle region of the cavity). To do this, the indenter was applied to dentin with a force of $50 \mathrm{~g}$ for 10 seconds. Finally, one sample out of each group was explored under Field-Emission Scanning Electron Microscopes (FESEM; Tescan, Brno, Czech Republic). After the standard preparation, the specimen was mounted in aluminum stops and then coated with gold by the sputter method. Lastly, the dentinal surface of the specimen was evaluated in the closest location to the cavity floor with a magnification of $\times 5000$.

\section{Statistical Methods}

The statistical appraisal was computed using SPSS 18. After receiving normal distribution using the ShapiroWilk test, the microhardness value was analyzed by twoway ANOVA and the post-hoc Games-Howell test $(P$ value $<0.05)$.

\section{Results}

In this in vitro study, 64 samples were tested within 4 groups at 3 different depths. First, the normal distribution of the data was evaluated by the Shapiro-Wilk test. It was found that the data in all groups followed the normal distribution $(P>1620.05)$. Therefore, parametric tests were used in data analysis.

Table 2 shows the mean and standard deviation of microhardness based on different depths. The two-way ANOVA test indicated that the groups had significant differences $(P=0.00)$.

Then, the post hoc Games-Howell test was performed for further comparison, the results of which are given in Tables 3 to 5 and Figure 1. According to Tables 2 and 3 , the lowest level of hardness at 20-micron depth was observed for the control group, which was significantly different from the glass ionomer, bioactive glass and laser groups ( $P=0.00, P=0.02, P=0.00$, respectively), but other groups did not show significant difference.

According to Tables 2 and 4, the results at a depth of $50 \mu \mathrm{m}$ were similar to those in Table 3, except that the difference between the laser and the bioactive glass was significant $(P=0.012)$ and the laser hardness was higher.

As shown in Tables 2 and 5, the microhardness value at $100 \mu \mathrm{m}$ for the control group was the lowest, which had a significant difference with the glass ionomer and the laser $(P=0.012, P=0.00)$, but with no significant difference was observed for bioactive glass $(P=0.153)$. The laser also had a significant difference with the bioactive glass $(P=0.09)$.

Table 3. The Comparison of Groups Based on the Games-Howell Post Hoc Test at a Depth of $20 \mu \mathrm{m}$

\begin{tabular}{lccc}
\hline Group I & Group II & Difference & $\boldsymbol{P}$ value \\
\hline Control & Glass ionomer & -12.2383 & 0.000 \\
Control & Bioactive glass & -9.5697 & 0.002 \\
Control & Laser & -14.5098 & 0.000 \\
Glass ionomer & Bioactive glass & 2.6686 & 0.671 \\
Glass ionomer & Laser & -2.2714 & 0.821 \\
Bioactive glass & Laser & -4.9401 & 0.404 \\
\hline
\end{tabular}

Table 2. Microhardness Values Based on Different Depths

\begin{tabular}{|c|c|c|c|c|c|c|c|}
\hline \multirow{2}{*}{ Groups } & & \multirow{2}{*}{ Frequency } & \multirow{2}{*}{ Mean } & \multirow{2}{*}{ Standard Deviation } & \multicolumn{2}{|c|}{ Mean With $95 \% \mathrm{Cl}$} & \multirow{2}{*}{$\begin{array}{c}\text { ANOVA Test } \\
\text { Results }\end{array}$} \\
\hline & & & & & Minimum & Maximum & \\
\hline \multirow{4}{*}{ At depth of $20 \mu \mathrm{m}$} & Control & 16 & 48.395 & 4.3084 & 46.379 & 50.411 & \multirow{4}{*}{0.000} \\
\hline & Glass ionomer & 16 & 60.633 & 5.1719 & 58.279 & 62.988 & \\
\hline & Bioactive glass & 16 & 57.965 & 8.4935 & 53.598 & 62.332 & \\
\hline & Laser & 16 & 62.905 & 10.8034 & 57.987 & 67.822 & \\
\hline \multirow{4}{*}{ At depth of $50 \mu \mathrm{m}$} & Control & 16 & 56.300 & 7.4903 & 52.794 & 59.806 & \multirow{4}{*}{0.000} \\
\hline & Glass ionomer & 16 & 68.895 & 6.4660 & 65.952 & 71.839 & \\
\hline & Bioactive glass & 16 & 64.265 & 7.2606 & 60.532 & 67.998 & \\
\hline & Laser & 16 & 76.352 & 14.5962 & 69.708 & 82.996 & \\
\hline \multirow{4}{*}{ At depth of $100 \mu \mathrm{m}$} & Control & 16 & 62.590 & 9.0013 & 58.377 & 66.803 & \multirow{4}{*}{0.000} \\
\hline & Glass ionomer & 16 & 70.767 & 6.7108 & 67.712 & 73.821 & \\
\hline & Bioactive glass & 16 & 68.588 & 7.8415 & 64.556 & 72.620 & \\
\hline & Laser & 16 & 81.281 & 14.6034 & 74.634 & 87.928 & \\
\hline
\end{tabular}


Table 4. The Comparison of Groups Based on the Games-Howell Post Hoc Test at a Depth of $50 \mu \mathrm{m}$

\begin{tabular}{lccc}
\hline Group I & Group II & Difference & $\boldsymbol{P}$ value \\
\hline Group I & Glass ionomer & -12.5952 & 0.000 \\
Control & Bioactive glass & -7.9647 & 0.012 \\
Control & Laser & -20.0524 & 0.000 \\
Glass ionomer & Bioactive glass & 4.6305 & 0.190 \\
Glass ionomer & Laser & -7.4571 & 0.166 \\
Bioactive glass & Laser & -12.0877 & 0.012 \\
\hline
\end{tabular}

Table 5. The Comparison of Groups Based on the Games-Howell Post Hoc Test at a Depth of $100 \mu \mathrm{m}$

\begin{tabular}{lccc}
\hline Group I & Group II & Difference & $\boldsymbol{P}$ value \\
\hline Control & Glass ionomer & -8.1767 & 0.012 \\
Control & Bioactive glass & -5.9982 & 0.153 \\
Control & Laser & -18.6910 & 0.000 \\
Glass ionomer & Bioactive glass & 2.1784 & 0.801 \\
Glass ionomer & Laser & $-10.5143^{*}$ & 0.027 \\
Bioactive glass & Laser & -12.6927 & 0.009 \\
\hline
\end{tabular}

It should be noted that in this depth, in contrast to the depth of 20 and $50 \mu \mathrm{m}$, there was a significant difference between the laser and the glass ionomer, which was higher for the laser $(P=0.027)$. There was still no significant difference between the glass ionomer and the bioactive glass, although the degree of hardness created by the glass ionomer was greater.

The results of dentin condition analysis in the below liner using FESEM in each group of bioactive glass, glass ionomer, and the laser showed that partial dentinal tubule occlusion compared to control group (Figure 2).

\section{Discussion}

The present results lead to the rejection of the null hypothesis. The results showed that the highest mean value of microhardness at the depth of $20 \mu \mathrm{m}$ was related to the laser, then the glass ionomer, and the bioactive glass respectively; they all had a significant difference with the control group that had the lowest microhardness value. Also, at the depth of $50 \mu \mathrm{m}$, the highest microhardness value was related to the laser, the glass ionomer, and the bioactive glass respectively, and the lowest was related to the control group. In this depth like the depth of 20 $\mu \mathrm{m}$, the control group had a significant difference with the types of liners and laser. At a depth of $100 \mu \mathrm{m}$, the microhardness value was like the previous depth, except that the difference between the control group and the bioactive glass was not significant. However, at this depth, the microhardness value of bioactive glass was still greater than the control group. According to these results, it can be said that the glass ionomer, the bioactive glass, and the laser can be used to remineralize the affected dentin, each of which has been studied in various studies.

In this study, it should be noted that the increase in the

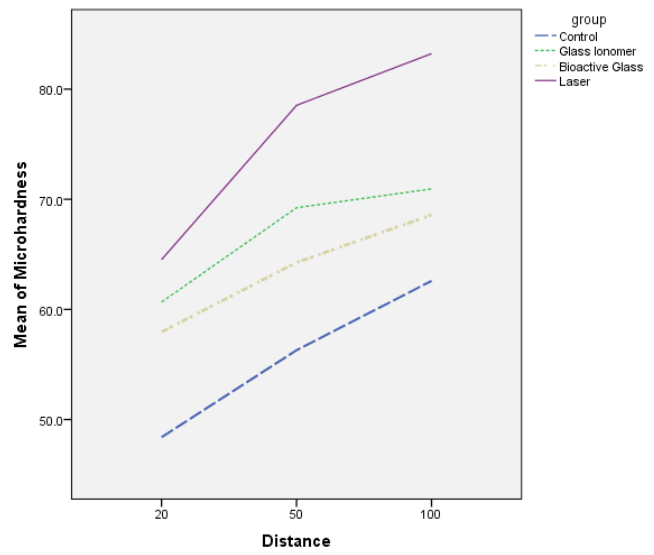

Figure 1. The Comparison of the Microhardness Among the Various Experimental Groups.
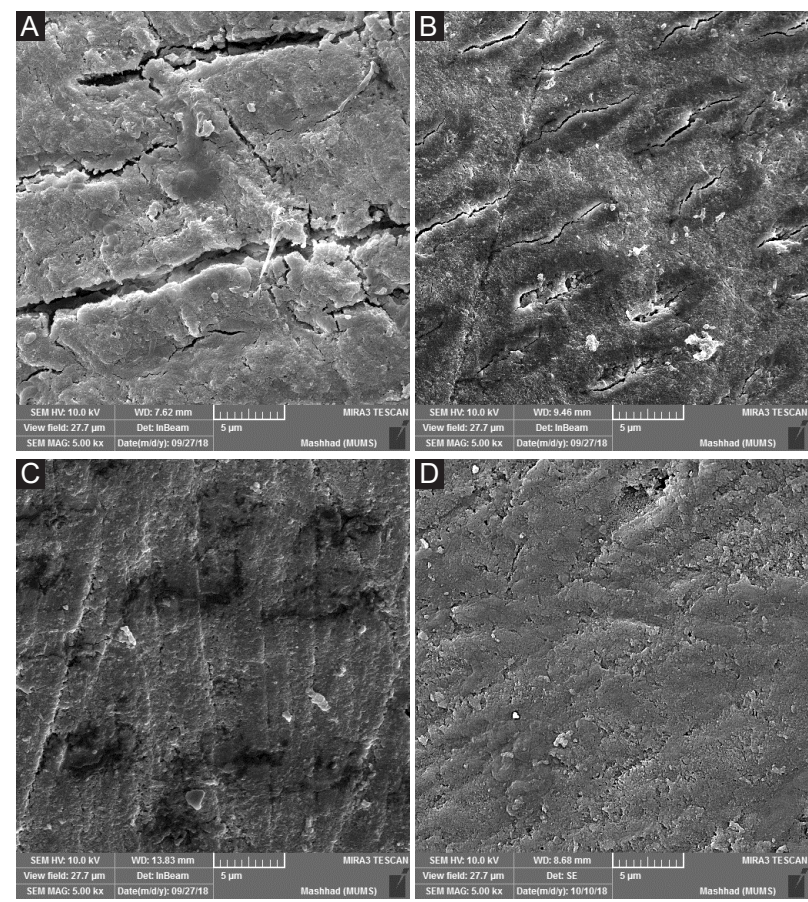

Figure 2. FESEM Images of the Dentin in 4 Groups: (A) Control, (B) Bioactive Glass, (C) Glass ionomer, (D) Laser.

hardness was observed from the cavity floor to the pulp unexpectedly in all groups even in the control group. This is due to the fact that the demineralizing solution was used in the preparation phase of the specimens to create the affected dentin. It can be said that the solution had a penetration at least at the depth of $100 \mu \mathrm{m}$. Therefore, with increasing the depth from the cavity floor to a depth of $100 \mu \mathrm{m}$, its penetration rate decreased and its hardness increased in all groups.

The bioactive glass is compatible with the tooth structure and has the ability to bond to hard and soft tissues. The bioactive behavior of these glasses is related to the formation of the biologically active hydroxyapatite layer. One of its most important properties is the antimicrobial 
property, which creates a bacterial-free environment that helps to repair and restore the lesion. ${ }^{14}$

One of the mechanisms for activating bioactive glass is that, after mixing the bioactive glass powder with phosphoric acid solution, sodium, phosphate and calcium ions are released into the acidic environment, and simultaneously, this acid gel can transfer calcium and phosphorus ions to the underneath tissue, and these ions penetrate existing tissue porosity. ${ }^{15}$

According to this study, the bioactive glass has been able to cause dentin remineralization, which has a significant difference with the control group up to a depth of $50 \mu \mathrm{m}$. This finding is consistent with many of the studies that have mentioned the affected dentin remineralization as one of the features of this substance. ${ }^{8,9,16-20}$

The absence of any difference between the control group and the bioactive glass at a depth of $100 \mu \mathrm{m}$ may be due to the fact that the penetration and influence area of the bioactive glass decreased after a depth of $50 \mu \mathrm{m}$, but the laser and glass ionomer groups, which had a significant difference with the control group, showed a sign of their penetration and influence.

The glass ionomer is a body-compatible substance with a low technical sensitivity that can do an ionic exchange with enamel and dentin. ${ }^{21}$

When a glass ionomer is used as a liner, fluoride ions can easily spread over the dentin surface and perform ion exchange with the tooth surface, which ultimately causes remineralization. ${ }^{22}$

In our study, the $\mathrm{pH}$ value of 5.8 was used in a twomonth storage environment. The reason for selecting the acidic environment was due to a positive relationship between the amount of fluoride released and the acidity of the environment. In other words, the acidity of the storage solution results in the release of more fluoride from the material and thus more absorption by the teeth. ${ }^{23}$

In this study, the glass ionomer increased remineralization, which was significant in comparison with the control group at all depths. This result is consistent with many studies, including Aykut-Yetkiner et al, ${ }^{5}$ Ngo et al, ${ }^{21}$ Itota et al, ${ }^{22}$ Kirsten et al, ${ }^{24}$ and Hara et al. ${ }^{25}$

There was no significant difference in the remineralization value between glass ionomer and bioactive glass, although the microhardness value created by glass ionomer was higher. Some studies have also examined these two materials. Among these, Prabhakar et al stated that when incorporating of bioactive glass into glass ionomer cements, their remineralizing property would increase. ${ }^{17}$

Some studies, emphasizing the remineralization of these two substances, have suggested that the bioactive glass is more likely to be more effective than GI and RMGI in dental restorations with open- or closedsandwich techniques and can be strongly considered as a liner. The reason for this difference between these studies and the present study may be attributed to this fact that the condition performance of the test and the preparation of the samples was not the same..$^{26,27}$

Erbium YAG Laser Radiation is a modern and promising technique that can successfully be used to treat dental caries. ${ }^{28}$ Recently, it has been demonstrated that the use of a laser not only involves the polymerization of restorative materials, teeth whitening and cavity preparation for restoration, but also includes application to prevent caries and dentin hypersensitivity. ${ }^{29}$

The laser absorption in tooth tissue has a thermal effect that is effective in the structural and chemical properties of hard dental tissue. The heat generated during laser radiation results in evaporation, the oxidation of organic components, the conversion of acid phosphate to pyrophosphates, and the reduction of carbonate content. These changes lead to the formation of compounds with less dissolution and greater stability, which may make the exposed substrate more resistant to demineralization..$^{30}$

In this test, the subablative parameters of the Erbium YAG Laser with a power of $0.5 \mathrm{~W}$ and a frequency of $10 \mathrm{~Hz}$ were used to prevent dental caries according to Fornaini et al and Moosavi et al. ${ }^{13,31}$ The use of the laser with subablative parameters and low-level energy, relative to higher energy, could prevent microcracks and damage to surrounding tissues. ${ }^{32}$

In a study, the subablative laser irradiation caused dense and compact regions with less open tubules due to the greater amount of tubule occlusion or recrystallization after surface heating. ${ }^{33}$

In this study, the microhardness value and thus the rate of remineralization using the Erbium YAG laser in all groups were significantly higher than the control group. This result is consistent with studies by Moosavi et $\mathrm{al}^{13}$ and Hossain et al. ${ }^{34}$

Perito et al also reported secondary caries that occurred less frequently in laser-prepared cavities compared with a bur. ${ }^{35}$

Ana et al pointed to the increased resistance of enamel and dentin using the Erbium laser in the treatment of dental caries. ${ }^{36}$

There are also some opposing studies. Among them, Celik et al found that the cavity preparation with a bur or an Erbium YAG laser did not significantly affect the microhardness and composition of dentin. ${ }^{37}$ Also, Apel et al concluded that the cavity preparation with the Erbium laser is not beneficial clinically in increasing the resistance to secondary caries. ${ }^{38}$

It seems that the observed difference between the studies can be related to the laser parameters used, such as pulse energy and its duration, pulse repetition frequency, the duration of laser radiation, and the application of water coolant.

In this test, there was a significant difference between the laser and the bioactive glass except at a depth of $20 \mu \mathrm{m}$, so that the dentin hardness was higher in the laser group. The laser and the glass ionomer were not 
significantly different at depths of 20 and $50 \mu \mathrm{m}$, but significantly superior at a depth of $100 \mu \mathrm{m}$, which may be due to the greater absorption of laser energy at this depth. Unfortunately, because no similar study was found in these cases, there is no possibility to compare with other studies.

The FESEM examination showed that the partial dentinal tubule occlusion was observed with sub-mineral materials in each of the groups of bioactive glass, glass ionomer and the laser compared to the control group, in line with Saffarpour et $\mathrm{al}^{19}$ and Moosavi et al. ${ }^{13}$

The results obtained in this study had an experimental nature, as it may be better to carry out this study on the basis of clinical design to determine whether the results of this study are in agreement with the clinic. It is recommended that a variety of different lasers and liners should be investigated on the affected dentin in future studies in order to scrutinize closely which of the cases would increase the dentin mineralization, particularly in the case of a laser whose results in this test are promising. It is necessary to determine exactly what parameters on the affected dentine should be used to increase tissue mineralization and not to damage the pulp.

\section{Conclusion}

According to the results obtained from the present study, the following conclusions are drawn:

1. In all groups, the lowest microhardness value was related to the control group; this difference with other groups was significant except at a depth of 100 $\mu \mathrm{m}$, which showed no significant difference between the control group and the bioactive glass.

2. The laser group had the highest microhardness value, whose difference with the control group was significant in all groups. There was a significant difference between the laser and the bioactive glass except for a depth of $20 \mu \mathrm{m}$. The laser and the glass ionomer had a significant difference only at a depth of $100 \mu \mathrm{m}$.

3. The microhardness value created by the glass ionomer was greater than the bioactive glass, but not significant in any depths.

\section{Conflict of Interests}

The authors declare no conflict of interest.

\section{References}

1. Winston AE, Bhaskar SN. Caries prevention in the 21st century. J Am Dent Assoc. 1998;129(11):1579-1587. doi: 10.14219/jada.archive.1998.0104.

2. Diefenderfer KE, Stahl J. Caries remineralization therapy: Implications for dental readiness. Mil Med. 2008;173(1 Suppl):48-50. doi: 10.7205/milmed.173.supplement_1.48.

3. Zhegova G, Rashkova M, Rocca JP. Minimally invasive treatment of dental caries in primary teeth using an Er:YAG Laser. Laser Ther. 2014;23(4):249-254. doi: 10.5978/ islsm.14-OR-18.
4. Ferreira G, Inés M. Bioactive materials in dentin remineralization. Odontoestomatologia. 2016;18(28):11-18.

5. Aykut-Yetkiner A, Simşek D, Eronat C, Çiftçioğlu M. Comparison of the remineralisation effect of a glass ionomer cement versus a resin composite on dentin of primary teeth. Eur J Paediatr Dent. 2014;15(2):119-121.

6. Shiozawa M, Takahashi H, Iwasaki N. Fluoride release and mechanical properties after 1-year water storage of recent restorative glass ionomer cements. Clin Oral Investig. 2014;18(6):1053-1060. doi: 10.1007/s00784-013-1074-4.

7. Goldstep F. Dental Remineralization: Simplified. Res Dent. 2012;102(12):12-24

8. Khoroushi M, Keshani F. A review of glass-ionomers: From conventional glass-ionomer to bioactive glass-ionomer. Dent Res J (Isfahan). 2013;10(4):411-20.

9. Vollenweider M, Brunner T, Knecht S, Grass RN, Zehnder $\mathrm{M}$, Imfeld $\mathrm{T}$, et al. Remineralization of human dentin using ultrafine bioactive glass particles. Acta Biomater. 2007;3(6): 936-43. doi: 10.1016/j.actbio.2007.04.003.

10. Nokhbatolfoghahaie $\mathrm{H}$, Chiniforush N, Shahabi S, Monzavi A. Scanning Electron Microscope (SEM) evaluation of tooth surface irradiated by different parameters of Erbium: Yttrium Aluminium Garnet (Er:Yag) laser. J Lasers Med Sci. 2012;3(2):51-5. doi: 10.22037/jlms.v3i2.2831.

11. Pahlavan A, Mehmanchi M, Ranjbar Omrani L, Chiniforush N. Effect of air abrasion and erbium-doped yttrium aluminum garnet (Er: YAG) laser preparation on shear bond strength of composite to dentin. J Lasers Med Sci. 2013;4(3):127-30. doi: 10.22037/jlms.v4i3.4141.

12. Chiniforush N, Nokhbatolfoghahaei H, Monzavi A, Pordel E, Ashnagar S. Surface treatment by different parameters of erbium: yttrium-aluminum-garnet (Er:YAG) laser: scanning electron microscope (SEM) evaluation. J Lasers Med Sci. 2016;7(1):37-9. doi:10.15171/jlms.2016.08.

13. Moosavi H, Ghorbanzadeh S, Ahrari F. Structural and morphological changes in human dentin after ablative and subablative Er:YAG laser irradiation. J Lasers Med Sci. 2016;7(2):86-91. doi: 10.15171/jlms.2016.15.

14. Abbasi Z, Bahrololouom M, Shariat MH, Bagheri R. Bioactive glasses in dentistry: a review. J Dent Biomater. 2015;2(1):1-9.

15. Bakry A, Takahashi H, Otsuki M, Tagami J. The durability of phosphoric acid promoted bioglass-dentin interaction layer. Dent Mater. 2013;29(4):357-64. doi: 10.1016/j. dental.2012.12.002.

16. Wang Z1, Jiang T, Sauro S, Pashley DH, Toledano M, Osorio $\mathrm{R}$, et al. The dentine remineralization activity of a desensitizing bioactive glass-containing toothpaste: An in vitro study. Aust Dent J. 2011;56(4):372-81. doi: 10.1111/j.1834-7819.2011.01361.x

17. Prabhakar AR, Paul MJ, Basappa N. Comparative evaluation of the remineralizing effects and surface microhardness of glass ionomer cements containing bioactive glass (S53P4): An in vitro Study. Int J Clin Pediatr Dent. 2010;3(2):69-77. doi: 10.5005/jp-journals-10005-1057.

18. Tantbirojn D, Feigal RJ, Ko CC, Versluis A. Remineralized dentin lesions induced by glass ionomer demonstrate increased resistance to subsequent acid challenge. Quintessence Int. 2006;37(4);273-81.

19. Saffarpour M, Mohammadi M, Tahriri M, Zakerzadeh A. Efficacy of modified bioactive glass for dentin 
remineralization and obstruction of dentinal tubules. $J$ Dent (Tehran). 2017; 14(4):212-222.

20. Chatzistavrou X, Velamakanni S, DiRenzo K, Lefkelidou A, Fenno JC, Kasuga T, et al. Designing dental composites with bioactive and bactericidal properties. Mater Sci Eng C Mater Biol Appl. 2015;52:267-72. doi: 10.1016/j. msec.2015.03.062.

21. Ngo HC, Mount G, Mc Intyre J, Tuisuva J, Von Doussa RJ. Chemical exchange between glass-ionomer restorations and residual carious dentine in permanent molars: an in vivo study. J Dent. 2006;34(8):608-13. doi: 10.1016/j. jdent.2005.12.012.

22. Itota T, Nakabo S, Torii Y, Narukami T, Doi J, Yoshiyama M. Effect of fluoride-releasing liner on demineralized dentin. Quintessence Int. 2006;37(4):297-303.

23. Taq AA, Abdal AK, Dawood AI. The effect of $\mathrm{pH}$ on fluoride release of glass ionomer based restorative materials. Inter J Dent Sci Res. 2016;4(3):52-57.

24. Kirsten GA, Takahashi MK, Rached RN, Giannini M, Souza EM. Microhardness of dentin underneath fluoridereleasing adhesive systems subjected to cariogenic challenge and fluoride therapy. J Dent. 2010;38(6):460468. doi: 10.1016/j.jdent.2010.02.006

25. Hara AT, Turssi CP, Ando M, González-Cabezas C, Zero DT, Rodrigues AL Jr, et al. Influence of fluoride-releasing restorative material on root dentine secondary caries in situ. Caries Res. 2006;40(5):435-9. doi: 10.1159/000094290.

26. Yli-Urpo H, Närhi T, Söderling E. Antimicrobial effects of glass ionomer cements containing bioactive glass (S53P4) on oral micro-organisms in vitro. Acta Odontol Scand. 2003;61(4):241-6. doi: 10.1080/00016350310004719.

27. Mickenautsch S, Mount G, Yengopal V. Therapeutic effect of glass-ionomers: An overview of evidence. Aust Dent J. 2011;56(1):10-15. doi: 10.1111/j.1834-7819.2010.01304.x.

28. Fekrazad R,Chiniforush N. One Visit Providing Desirable Smile by Laser Application. J Lasers Med Sci 2014;5(1):4750.

29. Ehlers V, Ernst CP, Reich M, Kämmerer P, Willershausen B. Clinical comparison of gluma and Er:YAG laser treatment of cervically exposed hypersensitive dentin. Am J Dent. 2012;25(3):131-5.

30. Ahrari F, Poosti M, Motahari P. Enamel resistance to demineralization following Er:YAG laser etching for bonding orthodontic brackets. Dent Res J (Isfahan). 2012;9(4):472-7.

31. Fornaini C, Brulat N, Milia G, Rockl A, Rocca JP. The use of sub-ablative Er:YAG laser irradiation in prevention of dental caries during orthodontic treatment. Laser Ther. 2014;23(3): 173-81. doi: 10.5978/islsm.14-OR-13.

32. Liu Y, Hsu CY, Teo CM, Teoh SH. Subablative Er:YAG laser effect on enamel demineralization. Caries Res. 2013;47(1):63-68. doi: 10.1159/000343573.

33. Souza-Gabriel AE, Chinelatti MA, Pecora JD, Palma-Dibb RG, Corona SA. Dentin microhardness and subsurface morphology after Er:YAG laser cavity preparation using different parameters. J Dent Child (Chic). 2009;76(1):58-66.

34. Hossain M, Nakamura Y, Murakami Y, Yamada Y, Matsumoto K. A comparative study on compositional changes and Knoop hardness measurement of the cavity floor prepared by Er:YAG laser irradiation and mechanical bur cavity. J Clin Laser Med Surg. 2003;21(1):29-33. doi: 10.1089/10445470360516716.

35. Perito MA, Jorge AC, de Freitas PM, Cassoni A, Rodrigues JA. Cavity preparation and influence of restorative materials on the prevention of secondary caries. Photomed Laser Surg. 2009;27(5):729-734. Laser Phys. 2006,16(5):865-75. doi:10.1134/S1054660X06050197.

36. Ana PA, Bachmann L, Zezell DM. Lasers effects on enamel for caries prevention. Laser Phys. 2006,16(5):865-75. doi:10.1134/S1054660X06050197.

37. Celik EU, Ergücü Z, Türkün LS, Türkuün M. Effect of different laser devices on the composition and microhardness of dentin. Oper Dent. 2008;33(5):496-501. doi: 10.2341/07-127.

38. Apel C, Schäfer C, Gutknecht N. Demineralization of Er:YAG and Er,Cr:YSGG laser-prepared enamel cavities in vitro. Caries Res. 2003;37(1):34-7. doi: 10.1159/000068228. 